\title{
Characteristics of Cellulolytic Cillobacteria from the Rumens of Sheep Fed Teff (Eragrostis tef) Hay Diets
}

\author{
By N. O. VAN GYLSWYK AND J. P. L. HOFFMAN \\ National Chemical Research Laboratory, South African Council for Scientific \\ and Industrial Research, Pretoria, Republic of South Africa
}

(Accepted for publication 20 November 1969)

SUMMAR Y

Nine isolates of cellulolytic, Gram-positive motile rods obtained from the rumen contents of sheep fed on teff hay were identified as belonging to the genus Cillobacterium Prévot. In most respects the organisms resembled C. cellulosolvens and it is proposed that the definition be extended to include the characteristics of the present strains.

\section{INTRODUCTION}

During a study of the cellulolytic flora in the rumens of sheep fed on diets of teff hay supplemented in different ways (van Gylswyk, I969) Gram-positive, motile cellulolytic rods in addition to cocci and Butyrivibrio-like rods were isolated. In no case were these rods as plentiful as the other cellulolytic organisms. However, their consistent occurrence indicates that they probably form part of the normal cellulolytic flora of the rumen when low-protein teff hay is fed, with or without certain supplements. Preliminary examination of the isolates revealed several points of resemblance to Cillobacterium cellulosolvens, a cellulolytic bacterium from the rumen of cattle first described by Bryant, Small, Bouma \& Robinson (1958). Since, to our knowledge, no further isolations of this organism have been reported, and since the description of this species was based on the characteristics of a single strain it was decided to characterize in detail a group of nine isolates resembling C. cellulosolvens.

\section{METHODS}

Isolation. The nine isolates studied were obtained from the rumen of four sheep fed differently supplemented teff hay diets (van Gylswyk, 1969).

Culture techniques. These were adapted from those used by Bryant \& Burkey (I953) and Kistner (1960). Anaerobic conditions were obtained by purging with oxygen-free gases. Traces of oxygen in the commercial gases were removed by passing the latter, together with about $2 \%$ hydrogen, through a 'Deoxo' catalyst cartridge (Engelhard Industries Ltd., London, U.K.). Inocula were transferred with sterile syringes. Incubation temperature was $38 \pm \mathrm{I}^{\circ}$, except in the case of temperature-tolerance tests. Time of incubation was generally about I week, except for the cellulose-containing medium, which was incubated for about I month. Two separate runs were conducted for all the tests, except the determinations of succinate and $\mathrm{C}_{2}$ to $\mathrm{C}_{5}$ volatile fatty acids. The organisms were cultured in media with initial $\mathrm{pH}$ values of $6 \cdot 8 \pm 0 \cdot \mathrm{I}$. 
Media. Except where otherwise stated the media contained the following constituents (g./1.): $\mathrm{K}_{2} \mathrm{HPO}_{4}, 0.225 ; \mathrm{KH}_{2} \mathrm{PO}_{4}, 0.225 ; \mathrm{NaCl}, 0.45 ;\left(\mathrm{NH}_{4}\right)_{2} \mathrm{SO}_{4}, 0.45 ; \mathrm{CaCl}_{2}, 0.045$; $\mathrm{MgSO}_{4} \cdot 7 \mathrm{H}_{2} \mathrm{O}, 0 \cdot 09 ; \mathrm{NaHCO}_{3}, 6 \cdot 37 ;$ cysteine hydrochloride, $0.25 ; \mathrm{Na}_{2} \mathrm{~S} .9 \mathrm{H}_{2} \mathrm{O}, 0.25$; cellobiose, 5; indigo carmine, 0.005 and rumen fluid from sheep fed on lucerne hay, $400 \mathrm{ml}$. (partly clarified by centrifuging at $1500 \mathrm{~g}$ for $20 \mathrm{~min}$.). The basal medium was sterilized by autoclaving ( $12 \mathrm{I}^{\circ} / 25 \mathrm{~min}$.) and $\mathrm{NaHCO}_{3}$ added as heat-sterilized and cellobiose as filter-sterilized, concentrated oxygen-free solutions. The cysteine hydrochloride and sodium sulphide were prepared as a combined, concentrated solution under nitrogen, made alkaline and heat-sterilized before addition to the medium. This medium was equilibrated with a gas phase containing $98 \% \mathrm{CO}_{2}$ and $2 \% \mathrm{H}_{2}$ (Medium I). For the preparation of maintenance slopes the sodium sulphide was omitted, the cysteine hydrochloride was increased to $0.5 \mathrm{~g}$., and $15 \mathrm{~g}$. agar was added.

For the fermentation tests a medium containing one tenth of the above concentration of $\mathrm{NaHCO}_{3}$ and $20 \%$ rumen fluid was used. This medium was equilibrated with $88 \% \mathrm{~N}_{2} / 10 \% \mathrm{CO}_{2} / 2 \% \mathrm{H}_{2}$. In the second run the rumen fluid was clarified by centrifuging at about $23,000 \mathrm{~g}$ for $2 \mathrm{hr}$ to facilitate visual detection of growth. The soluble sugars were added as sterile millipore-filtered solutions while insoluble substances were heat-sterilized together with the basal medium. The final concentration in each case was $5 \mathrm{~g}$./1. For the temperature-tolerance tests the medium was similar to that used for the fermentation tests except that it contained $5 \mathrm{~g}$. cellobiose. The medium for determining the relation of the organisms to free oxygen was as medium $\mathrm{I}$, but contained 0.637 g. $\mathrm{NaHCO}_{3}$, I5 g. agar, 10 g. Trypticase (Baltimore Biological Laboratories), I g. cellobiose ( $5 \mathrm{~g}$. in the first run), and I mg. resazurin instead of indigo carmine. The medium was prepared under $90 \% \mathrm{~N}_{2} / 10 \% \mathrm{CO}_{2}$ and after inoculation was incubated under air $/ 10 \% \mathrm{CO}_{2}$. To test for growth in the absence of $\mathrm{CO}_{2}, \mathrm{NaHCO}_{3}$ was omitted from medium $\mathrm{I}$ and the gas phase consisted of $98 \% \mathrm{~N}_{2} / 2 \% \mathrm{H}_{2}$. For testing growth in the absence of rumen fluid, this constituent was replaced in medium I by $15 \mathrm{~g}$. Trypticase and $5 \mathrm{~g}$. yeast extract (Difco) in an equivalent volume of water. For the gelatin liquefaction test $50 \mathrm{~g}$. gelatin and $15 \mathrm{~g}$. Trypticase were added to medium I. One grarn $\mathrm{KNO}_{3}$ and $20 \mathrm{~g}$. Trypticase were added to medium I to test for the formation of nitrite from nitrate. Trypticase $(20 \mathrm{~g}$.) was also added to the test media for indole and acetylmethyl-carbinol production. In the case of the latter three media indigo carmine was omitted because the colour of the oxidized indicator hampered the interpretation of these tests. For testing for hydrogen sulphide production the organisms were grown in medium $I$ to which was added $0.5 \mathrm{~g}$. ferric ammonium citrate, $5 \mathrm{~g}$. agar and $\mathrm{I} 5 \mathrm{~g}$. Trypticase. Hydrogen production was determined after growth in medium I plus $12 \mathrm{~g}$. cellobiose, equilibrated with hydrogenfree $\mathrm{CO}_{2}$. Production of volatile fatty acids was determined in medium I containing $12 \mathrm{~g}$. Whatman No. I filter-paper cellulose (which had been ball-milled for $72 \mathrm{hr}$ ) as the only added carbohydrate. The organisms were examined for motility after growth on a medium similar to that for maintenance except that it contained only $\mathbf{I}$ g. of cellobiose.

Identification tests. In the tests for temperature tolerance, ability to ferment carbohydrates and ability to grow in the absence of $\mathrm{CO}_{2}$, a change in $\mathrm{pH}$ of more than 0.3 was taken as indicative of growth. For testing the susceptibility of the organisms to free oxygen deep stabs were made in test tubes containing the solid medium. Growth in the absence of rurnen fluid was assessed by the development of turbidity. For the 
gelatin liquefaction test (Conn, I95I) cultures were incubated for about 2 weeks. In one series of tests residual gelatin was precipitated with $\mathrm{HgCl}_{2}$ while in the second, solidification at low temperature was used as criterion of non-liquefaction. Acetylmethyl-carbinol was detected by a method employing $\alpha$-naphthol (Conn, I95I). The production of indole was assessed by the method of Kovács (I928). The detection of hydrogen as a fermentation product of cellobiose, and the quantitative measurement of $\mathrm{C}_{2}$ to $\mathrm{C}_{5}$ volatile fatty acids as fermentation products of cellulose (after extraction with ether), were done by gas chromatography. Formate was determined by the method of Rabinowitz \& Pricer (1962), lactate by the method of Elsden \& Gibson (1954), succinate by a method described by Cohen (1959) and ethanol by the method of Bonnichsen (1962). Flagella stains were made according to the method of Leifson (I95I) using basic fuchsin instead of pararosaniline and a staining time of I4 min.

\section{RESULTS}

Colony morphology. Surface colonies on $0.5 \%$ cellobiose, $40 \%$ rumen fluid, agar slopes were circular, convex entire, and about $\mathrm{I} \mathrm{mm}$. in diameter at $\mathrm{I} 8 \mathrm{hr}$ after inoculation. Surface colonies of the organisms within the clearings produced on cellulose agar films after 2 to 4 weeks were usually entire, flat and translucent and often extended to the outer limit of the zone of clearing. Deep colonies were generally lenticular. Cellulolysis within the clearings was complete.

Morphology and Gram reaction. In young cultures grown on $0 . \mathrm{I} \%(\mathrm{w} / \mathrm{v})$ cellobiose rumen fluid, agar medium, the organisms occurred as Gram-positive rods with pointed ends, arranged in chains (Pl. I, fig. I). As the cultures became older, the chains broke up and the proportion of organisms showing a Gram-negative reaction increased markedly (Pl. I, fig. 2). A proportion of the organisms showed a coccoid morphology. At this stage the rods were $0.5 \mu$ to $3 \mu$ long (typically $0.9 \mu$ to $2 \mu$ ) by $0.5 \mu$ to $\mathrm{I} \mu$ wide (typically $0.6 \mu$ to $0.9 \mu$ ). In still older cultures the organisms occurred singly and in pairs, and comprised a mixture of Gram-positive and Gram-negative rods (Pl. I, fig. 3).

Motility and flagella. In young cultures, where chain formation was abundant, no motility could be observed and there was no evidence of flagella. In somewhat older cultures, where the chains had largely broken up, organisms often showed restricted movement, which was more than could be attributed to Brownian movement alone. In such cultures were organisms with developing flagella or 'buds' (P1. I, fig. 4). With older cultures very active 'tumbling' motility was observed in all the strains and flagella could be demonstrated. The flagella occurred in numbers of 2 to 9 per organism and the arrangement was peritrichous (Pl. I, fig. 5, 6, 7, 8, 9).

Fermentation tests. All the isolates fermented the following carbon sources, the figures in parentheses indicating the final $\mathrm{pH}$ values after incubation for at least 7 days; glucose $\left(5^{\cdot} \cdot\right.$ to $\left.5 \cdot 5\right)$, galactose $(5 \cdot 3$ to $6 \cdot 4)$, maltose $(5 \cdot 0$ to $5 \cdot 5)$, lactose $(5 \cdot 6$ to $6 \cdot 1)$, sucrose $(5 \cdot 1$ to $5 \cdot 6)$, inulin $(5 \cdot 4$ to $6 \cdot 4)$, aesculin $(5 \cdot 3$ to 5.9$)$, salicin $(5 \cdot 2$ to 5.6$)$, pectin $(5 \cdot 6$ to $6 \cdot 4)$. Ball-milled Whatman No. I filter-paper cellulose was always vigorously attacked and almost completely solubilized. None of the isolates fermented L-arabinose, D-xylose, D-mannose, L-rhamnose, trehalose, dextrin, starch, glycerol, mannitol, inositol, or DL-sodium lactate. Fructose was fermented by isolates I, 5, 6, 7 and 8, but, with the exception of isolate 5 , the $\mathrm{pH}$ change was very slight. Raffinose was 
fermented by all isolates except $\mathrm{I}$ and 8 ; the final $\mathrm{pH}$ values ranging from $5 \cdot 4$ to $6 \cdot 0$. Xylan was not fermented by isolates I, 3, 4, 6 and 8 , while the reaction of the remaining strains was weakly positive in one run and negative in the other.

Other tests. All the strains were obligate anaerobes. None of the strains produced catalase, indole, $\mathrm{H}_{2} \mathrm{~S}$ or ethanol. Gelatin was not liquefied, and no nitrite was found after growth in nitrate-containing medium. The Voges-Proskauer reaction was weakly positive. Good growth occurred in $\mathrm{CO}_{2}$-free medium (final $\mathrm{pH} 5.0$ to 5.4 ), and in medium containing Trypticase/yeast extract instead of rumen fluid. The strains showed very poor growth at $45^{\circ}$ and no growth at $22^{\circ}$. At temperatures of $37^{\circ}$ to $39^{\circ}$

Table I. Acids produced $(+)$ or utilized $(-)$ by nine strains of cellulolytic, motile Gram-positive rods isolated from the rumen of sheep fed teff hay diets

$\begin{array}{lcccccccccc}\begin{array}{c}\text { Acid } \\ \text { produced } \\ \text { or utilized }\end{array} & \mathrm{I}_{\mathrm{I}} & 2 & 3 & 4 & 5 & 6 & 7 & 8 & 9 \\ \text { Formate } & +\mathrm{I} .22 & +\mathrm{I} .58 & +\mathrm{I} \cdot \mathrm{I} 4 & +0.99 & +\mathrm{I} .07 & +\mathrm{I} \cdot \mathrm{I} 2 & +\mathrm{I} \cdot 3 \mathrm{I} & +\mathrm{I} \cdot 47 & +\mathrm{I} .6 \mathrm{I} \\ \text { Acetate } & -0.78 & -\mathrm{I} .07 & -\mathrm{I} .22 & -\mathrm{I} .43 & -0.26 & -0.83 & -0.82 & -\mathrm{I} \cdot 2 \mathrm{I} & -2.37 \\ \text { Propionate } & -0.62 & -0.64 & -0.72 & -0.69 & -0.63 & -0.55 & -0.62 & -0.65 & -0.90 \\ \text { Isobutyrate } & +0.0 \mathrm{I} & -0.0 \mathrm{I} & 0 & -0.0 \mathrm{I} & -0.0 \mathrm{I} & 0 & 0 & +0.0 \mathrm{I} & -0.02 \\ \text { Butyrate } & +2.04 & +\mathrm{I} .55 & +2.25 & +\mathrm{I} .55 & +\mathrm{I} \cdot 77 & +\mathrm{I} \cdot 85 & +2.52 & +2 . \mathrm{I} 3 & +\mathrm{I} \cdot 2 \mathrm{I} \\ \text { Isovalerate } & 0 & -0.0 \mathrm{I} & -0.0 \mathrm{I} & -0.0 \mathrm{I} & -0.0 \mathrm{I} & -0.0 \mathrm{I} & 0 & 0 & -0.03 \\ \text { Valerate } & +0.49 & +0.4 \mathrm{I} & +0.58 & +0.4 \mathrm{I} & +0.45 & +0.46 & +0.60 & +0.55 & +0.3 \mathrm{I} \\ \text { Lactate } & +3.28 & +4.86 & +4.65 & +4.79 & +4.73 & +4.85 & +4.04 & +3.62 & +4.53\end{array}$

Values expressed as $\mathrm{m}-$ mole/ $100 \mathrm{ml}$. medium.

The uninoculated medium contained the following (m-mole/I00 ml.): formate, 0.19 ; acetate, 5.50 ; propionate, $\mathrm{I} \cdot 57$; isobutyrate, 0.06 ; butyrate, 0.79 ; isovalerate, 0.07 ; valerate, $0 . \mathrm{II}$; lactate, $0 . \mathrm{II}$.

good growth was always obtained. No significant growth was noted in a medium containing peptone as sole carbon source. Hydrogen was produced by all the strains, although in small quantities $(2.0 \%$ to $3.3 \%(\mathrm{v} / \mathrm{v})$ of the gas phase). Results showing the net production or utilization of formate, lactate and $\mathrm{C}_{2}$ to $\mathrm{C}_{5}$ volatile fatty acids are given in Table I. Figures for formate and lactate are mean values for the two separate runs, whereas the figures given for the other acids represent determinations done on the first run only. The mean recovery of acids in the first run for the nine strains was $89 \%$ of the titratable acid obtained after ether extraction of the cultures. The corresponding figure for the uninoculated culture medium was $97 \%$. None of the strains produced succinate.

\section{DISCUSSION}

In so far as the nine isolates were heterotrophic, Gram-positive anaerobic rods, actively motile by means of peritrichous flagella and fermenting a wide range of carbohydrates, the end products including hydrogen, formate, butyrate, valerate and lactate, they belong to the genus Cillobacterium Prévot (Bergey's Manual|1957). The fact that they did not produce gas in peptone broth medium may have been due to the deficiency of some growth factor in this medium.

Of the seven species that have been described as belonging to the genus Cillobacterium (Bergey's Manual I957; Bryant et al. 1958) the present isolates most closely resemble C. cellulosolvens (Bryant et al. 1958), particularly in so far as they were isolated from the rumen and were cellulolytic, in contrast to other species of the genus 
for which cellulolysis has not been reported. The principal differences between the type culture of $C$. cellulosolvens and our isolates lie in the nature and proportions of end products formed in the fermentation of carbohydrates. The type culture was practically homofermentative; the lactic acid produced constituted $94 \%$ of the carbon of the products recovered, and only small amounts of formate and acetate were produced. Hydrogen, formate, butyrate, valerate and lactate were produced, while acetate and propionate were utilized, by the present strains. In this respect they conform more closely to the definition of the genus Cillobacterium than does the type strain. Lesser differences include the ability of the present strains to ferment lactose as opposed to the type culture which did not. Organisms of the type culture had a maximum of four flagella whereas the present strains had up to nine. Even though the latter may differ from the type culture to the extent that the creation of a new species might be warranted, it is felt that the species name $C$. cellulosolvens is very apt as the organisms are very actively cellulolytic whereas the other members of the genus thus far described do not attack cellulose.

On the basis of the present work it is suggested that the description of the species Cillobacterium cellulosolvens (Bryant et al. 1958) be amended to include organisms that produce hydrogen, butyrate and valerate in addition to formate and lactate; that can utilize acetate and propionate; that have up to nine flagella per rod; that ferment galactose and pectin; that do not ferment D-mannose, L-rhamnose, trehalose and inositol and may or may not ferment fructose, lactose, raffinose and xylan; that may show slight production of acetyl-methyl-carbinol; that grow in the absence of carbon dioxide and that may show a little growth at $45^{\circ}$.

Cillobacterium cellulosolvens was often found in the $10^{-7}$ dilution of rumen ingesta from sheep conditioned to diets containing low-protein teff hay (van Gylswyk, I969). In cases where the organisms were found they occurred in numbers representing 2 to $13 \%$ of the mean level of the cellulolytic counts. It is quite possible that the organisms would have been found more regularly if a greater number of cellulolytic isolates had been obtained. The available data suggest that $C$. cellulosolvens normally occurs in numbers of at least $10^{6}$ per $g$. rumen contents from sheep fed on diets containing teff hay. In spite of the relatively low number of these bacteria in the rumen, when compared with, for instance, the number of cellulolytic ruminococci, they may nevertheless contribute significantly to cellulose breakdown as they have a high rate of cellulose digestion in vitro.

The authors wish to thank Dr A. Kistner for advice and interest in this work, $\mathrm{Mr} \mathrm{C}$. E. G. Roché for the determination of $\mathrm{C}_{2}$ to $\mathrm{C}_{5}$ volatile fatty acids, Mr P. G. Thiel for the determination of hydrogen and Mr A. M. du Bruyn for the photography.

\section{REFERENCES}

BonNichsen, R. (1962). Ethanol. Determination with alcohol dehydrogenase and DPN. In Methods of Enzymatic Analysis. Ed. by H. U. Bergmeyer. New York: Academic Press.

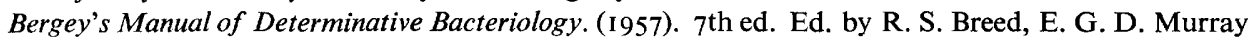
\& N. R. Smith. London: Baillière, Tindall \& Cox, Ltd.

Bryant, M. P. \& Burkey, L. A. (1953). Cultural methods and some characteristics of some of the more numerous groups of bacteria in the bovine rumen. Journal of Dairy Science 36, 205.

Bryant, M. P., Small, N., Bouma, C. \& Robinson, I. M. (1958). Characteristics of ruminal anaerobic cellulolytic cocci and Cillobacterium cellulosolvens n.sp. Journal of Bacteriology 76, 529. 
CoHen, P. P. (1959). Manometric estimation of metabolites and enzyme systems. In Manometric Techniques. 3rd ed. Ed. by W. W. Umbreit, R. H. Burris \& J. F. Stauffer. Minneapolis: Burgess Publishing Co.

ConN, H. J. ( I95I). Routine tests for the descriptive chart. Morphological and biochemical. Leaflet V. I 2th ed. In Manual of Methods for Pure Culture Study of Bacteria. Ed. by Committee of Bacteriological Technic of the Society of American Bacteriologists. Geneva, N.Y.: Biotech Publications.

ElsDen, S. R. \& GrBson, Q. H. (1954). The estimation of lactic acid using ceric sulphate. Biochemical Journal 58, I 54.

KISTNER, A. ( 1960 ). An improved method for viable counts of bacteria of the ovine rumen which ferment carbohydrates. Journal of General Microbiology 23565.

Kovács, N. (1928). Eine vereinfachte Methode zum Nachweis der Indolbildung durch Bakterien. Zeitschrift für Immunitätsforschung und Experimentelle Therapie 55, 311 .

LEIFSON, E. (195I). Staining, shape, and arrangement of bacterial flagella. Journal of Bacteriology 62, 377.

Rabinowitz, J. C. \& Pkicer, W. E. (1962). Formate. In Methods of Enzymatic Analysis. Ed. by H. U. Bergmeyer. New York: Academic Press.

van GyLSWYK, N. O. (1969). The effect of supplementing a low-protein hay on the cellulolytic bacteria in the rumen of sheep and on the digestibility of cellulose and hemicellulose. Journal of Agricultural Science, Cambridge (in the Press).

\section{EXPLANATION OF PLATE}

Cells and flagellated cells of Cillobacterium cellulosolvens.

Fig. I. Gram-stained preparation of young culture. $\times$ I 200 .

Fig. 2. Gram-stained preparation of somewhat older culture. $\times 1200$.

Fig. 3. Gram-stained preparation of a culture in which abundant growth had occurred. $\times 1200$.

Fig. 4. Leifson stain of a cell showing 'bud' formation. $\times 2400$.

Fig. $5,6,7,8$ and 9 . Leifson stain of flagellated cells. $\times 2400$. 

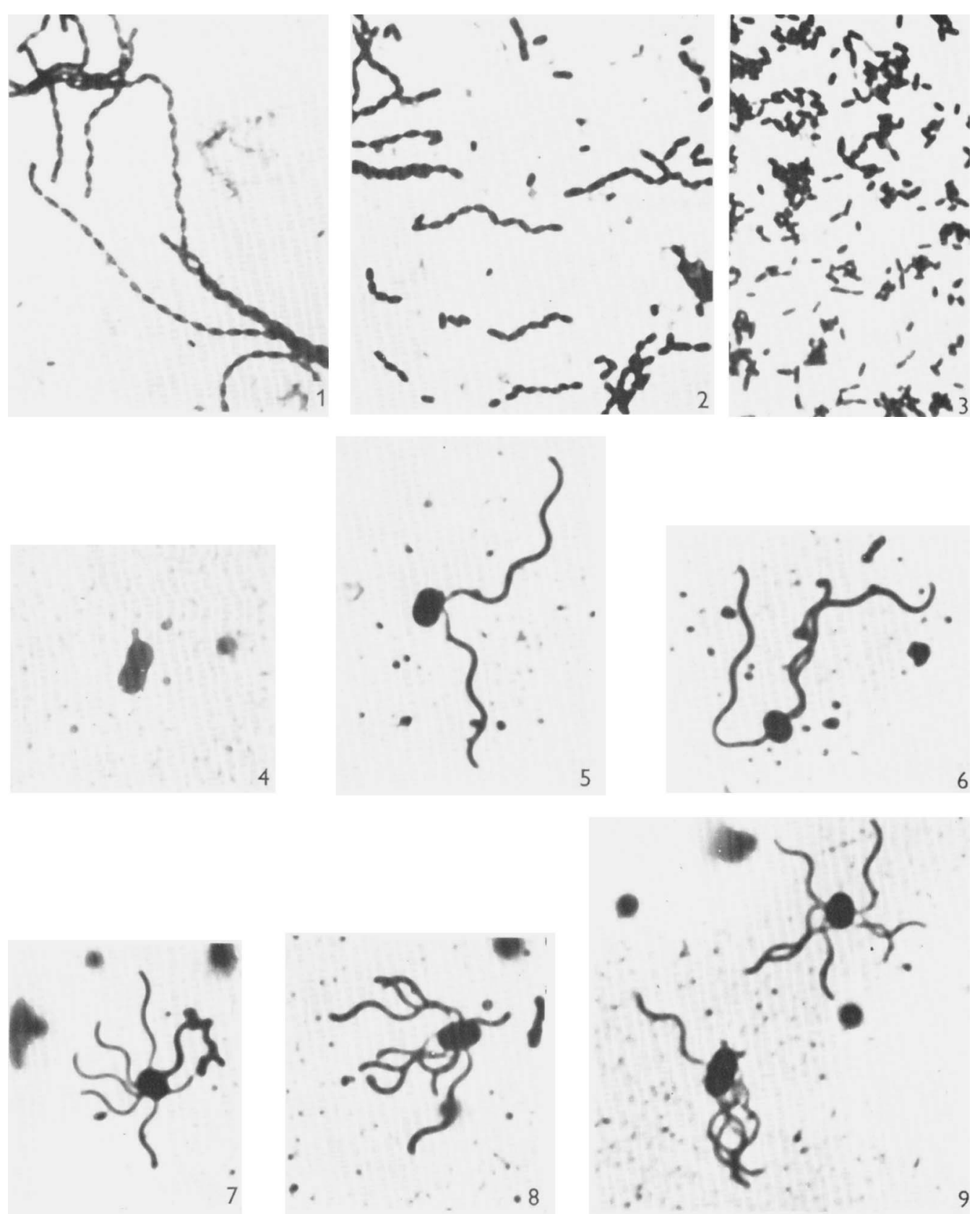